\title{
Fluorescent Nanoparticles Coated with a Somatostatin Analogue Target Blood Monocyte for Efficient Leukaemia Treatment
}

\author{
Ahmed A. H. Abdellatif ${ }^{1,2,3}$ (D) - Robert Hennig ${ }^{3}$ - Klaus Pollinger ${ }^{3}$ - Hesham M. Tawfeek ${ }^{4}$ - Abdellatif Bouazzaoui ${ }^{5,6}$. \\ Achim Goepferich ${ }^{3}$
}

Received: 7 May 2020 / Accepted: 23 September 2020 / Published online: 9 October 2020

(C) Springer Science+Business Media, LLC, part of Springer Nature 2020

\begin{abstract}
Background Leukaemia is the most prevalent form of cancer-causing death in a large number of populations and needs prompt and effective treatment. Chemotherapeutics can be used to treat leukaemia, but their pronounced killing effects to other living cells is still an issue. Active targeting to certain specific receptors in leukaemic cells is the best way to avoid damage to other living cells. Leukaemic cells can be targeted using novel nanoparticles (NPs) coated with a specific ligand, such as octreotide (OCD), to target somatostatin receptor type $2\left(\mathrm{SSTR}_{2}\right)$, which is expressed in leukaemic cells. Methods Amino-PEGylated quantum dots (QDs) were chosen as model NPs. The QDs were first succinylated using succinic anhydride and then coated with OCD. The reactivity and selectivity of the formulated QDs-OCD were studied in cell lines with well-expressed $\mathrm{SSTR}_{2}$, while fluorescence was
\end{abstract}

Electronic supplementary material The online version of this article (https://doi.org/I 0. I007/s I 1095-020-02938- I) contains supplementary material, which is available to authorized users.

Ahmed A. H. Abdellatif

a.abdellatif@qu.edu.sa; ahmed.a.h.abdellatif@azhar.edu.eg

Department of Pharmaceutics, College of Pharmacy, Qassim University, Buraydah 5 1452, Qassim, Kingdom of Saudi Arabia

2 Department of Pharmaceutics and Industrial Pharmacy, Faculty of Pharmacy, Al-Azhar University, Assiut 71524, Egypt

3 Department of Pharmaceutical Technology Department, Faculty of Chemistry and Pharmacy, Regensburg

University, 93040 Regensburg, Germany

4 Department of Industrial Pharmacy, Faculty of Pharmacy, Assiut University, 71526 Assiut, Egypt

5 Department of Medical Genetics, Faculty of Medicine, Umm Al-Qura University, P.O. Box 7I5, Makkah 21955, Saudi Arabia

6 Science and Technology Unit, Umm Al Qura University, P.O. Box 715, Makkah 21955, Saudi Arabia detected using confocal laser scanning microscopy (CLSM) and flow cytometry (FACS). Conclusively, QD-OCD targeting to blood cells was studied in vivo in mice and detected using inductively coupled plasma mass spectrometry and CLSM in tissues.

Results Highly stable QDs coated with OCD were prepared. FACS and CLSM showed highly definite interactions with overexpressed $\mathrm{SSTR}_{2}$ in the investigated cell lines. Moreover, the in vivo results revealed a higher concentration of QDs-OCD in blood cells. The fluorescence intensity of the QDs-OCD was highly accumulated in blood cells, while the unmodified QDs did not accumulate significantly in blood cells. Conclusion: The formulated novel QDs-OCD can target $\mathrm{SSTR}_{2}$ overexpressed in blood cells with great potential for treating blood cancer.

KEY WORDS fluorescent nanoparticles, leukaemia, active targeting · octreotide · PEGylated quantum dots · somatostatin receptors

\section{INTRODUCTION}

Leukaemia is a kind of blood cancer that begins in the bone marrow (19,21). This type of malignant cell is caused by the anomalous circulation of undeveloped white blood cells, which multiply in an uncontrolled manner. Leukaemia can likewise emerge in young people, and the most common form is called acute lymphoid leukaemia characterised by expansion of one cell type, whereas other cells responsible for the defence or for the oxygen transport becoming less $(18,25)$. Leukaemia starts in the blood and it can spread to other organs of the body, such as lymph nodes, liver, spleen, central nervous system and other organs (16,41). Effective targeting of chemotherapeutic medications to the places containing tumours could be a great advantage to patients with advanced metastatic tumours (54). Cytotoxic compounds linked to 
analogues of hormonal peptides could be an essential addition to oncological medical practitioners (4). Leukaemic cells within the body carry surface receptors that are specific for their particular type of cell. Somatostatin (SST) and its analogues and receptors play an important role in the proliferation of leukaemic cells as previously reported $(31,44)$. Somatostatin receptors are five subtypes $\left(\mathrm{SSTR}_{1-5}\right)$ have been detected in peripheral blood lymphocytes (PBLs) and mammalian leukaemic cells in lymphoblastic and nonlymphocytic leukaemia via somatostatin radio binding assays (28). The frequent incidence of $\mathrm{SSTR}_{2}$ in tumour cells makes $\mathrm{SSTR}_{2}$ a promising target for antitumor therapy. $\mathrm{SSTR}_{2}$ are abundantly present on the membrane of leukaemic cells. Thus, leukaemic cells can be easily detected and targeted using nanoparticulate systems coated with somatostatin analogues such as vapreotide (VAP) or octreotide (OCD) for efficient therapy and early detection $(29,56)$.

Nanoparticles are used as carriers for drug delivery, either by encapsulating an active substance or by physical or chemical absorption of drugs, which enable the nanoparticle to reach the cell surface easily $(5,15)$. Specific drug targeting to different body organs has numerous advantages for more efficient drug treatment compared with conventional therapy (4). Additionally, active binding has shown a significantly lower incidence of side effects and other toxic manifestations (13). QDs are semiconductor NPs unaffected by photobleaching with high stability in blood; hence, QDs have wide applications in vivo (7). Furthermore, QDs are well tolerated in different cell lines, and due to their unique properties derived from their size and structure, they could be used for detection, bioimaging, and targeting purposes (7-9).

Octreotide (OCD) is an effective SST analogue that shows higher internalization into cells with more $\mathrm{SSTR}_{2}$ on their surfaces compared with natural SST. Moreover, OCD can be easily attached to NPs to target different cancer cells. Almost all of the OCD can be conjugated to amine PEGylated QDs as a surrogate for PEGylated NPs to specifically target normal and diseased cells overexpressing SSTR $_{2}(24,62)$.

The purpose of this work was to study the potential of modified QDs with SST analogues to target $\mathrm{SSTR}_{2}$ located in blood cells for efficient treatment and early diagnosis of leukaemia. QD-PEG-amine was first conjugated to OCD using 1-ethyl-3-(3-dimethylaminopropyl) carbodiimide (EDC) and N-hydroxysuccinimide (NHS). The selectivity of the formulated QDs-OCD for $\mathrm{SSTR}_{2}$ was studied in different cell lines with well-expressed $\mathrm{SSTR}_{1-5}$. Moreover, the fluorescence was detected using CLSM and FACS. The targeting of QDs-OCD to blood cells was also investigated in vivo in an animal model.

\section{MATERIALS AND METHODS}

\section{Materials}

Octreotide acetate was obtained from ChemPep Co. (Wellington, USA). Quantum dots-PEG-amino (Qdot ${ }^{\circledR} 655$ ITK $^{\text {TM }}$ amino (PEG) quantum dots), Dulbecco's phosphatebuffered saline (pH 7.4), Dulbecco's modified Eagle's medium, and Leibovitz's L-15 medium were purchased from Life Technology (Darmstadt, Germany). Succinic anhydride, 1ethyl-3-(3-dimethylaminopropyl) carbodiimide, nitric acid, hydrochloric acid, Sephadex G-25, and $\mathcal{N}, \mathcal{N}$-diisopropylethylamine (DIPEA) were purchased from Sigma Aldrich (Darmstadt, Germany). Ultrafiltration tubes (100-kDa, Ultra-4 Millipore) were obtained from Amicon (Billerica, USA). Pancreatic carcinoid tumour cells were kindly supplied by Novartis Institutes (Basel, Switzerland). All glassware was carefully washed with freshly prepared aqua regia $(\mathrm{HCl}$ : $\mathrm{HNO}_{3}, 3: 1$ ), rinsed with Millipore water and oven-dried at $40^{\circ} \mathrm{C}$ for $3-4 \mathrm{~h}$ before use.

\section{Conjugation of Octreotide to QDs}

QDs-OCD were obtained by conjugating Qdot巴 655 ITK $^{\text {TM }}$ amino (PEG) quantum dots, (unmodified QDs) to OCD at the N-terminus of OCD (43) at pH 8.0 as adjusted with DIPEA. Succinic anhydride was reacted with QDs to form succinylated QDs using EDC as a water-soluble cross-linker (Fig. 1) $(36,57)$. For succinylation of the QDs, solid succinic anhydride (equimolar) was added to $15 \mu \mathrm{L}$ of $8.0 \mu \mathrm{M}$ QDs plus $2 \mathrm{~mL}$ of phosphate buffer at pH 9.0 and stirred at $600 \mathrm{rpm}$ for $15 \mathrm{~min}$. The reaction proceeded for $1 \mathrm{~h}$. The excess succinic anhydride was removed using Sephadex G-25 followed by centrifugation at $1800 \times \mathrm{g}$ for $5 \mathrm{~min}(35,51)$. Furthermore, the obtained succinylated QDs were resuspended in $500 \mu \mathrm{L}$ of water. Afterward, $100 \mu \mathrm{L}$ of $0.6 \mu \mathrm{M}$ OCD was added to the reaction mixture, incubated with $0.45 \mu \mathrm{M}$ EDC and $0.22 \mu \mathrm{M}$ NHS and stirred for an additional $3 \mathrm{~h}$ at room temperature. The final product, QDs-OCD, was filtered using Sephadex G-25 and then centrifuged at $1800 \times g$ for $10 \mathrm{~min}$ at $20^{\circ} \mathrm{C}(57)$.

\section{Quantum Dot Characterization}

The sizes and zeta potentials of the unmodified QDs and QDs-OCD were determined using a Malvern Zetasizer Nano ZS (Malvern Instruments GmbH, Herrenberg, Germany). Moreover, infrared spectra were recorded using a Bruker Tensor 27 Optics (Bruker BioSpin GmbH, Rheinstetten, Germany). Spectra were collected in the range of 400-4000 $\mathrm{cm}^{-1}$ using attenuated total reflectance Fourier transform infrared spectroscopy (ATR-FTIR) (10). For ${ }^{1} \mathrm{H}$ NMR measurements, QDs were dried under vacuum and then dissolved in $750 \mu \mathrm{L} \mathrm{D} \mathrm{D}_{2} \mathrm{O}$ using a Bruker DRX400 or 
Fig. I Conjugation of QDs-PEGamine (unmodified QDs) with OCD, the amino group of the QDs was succinylated and then conjugated to OCD.

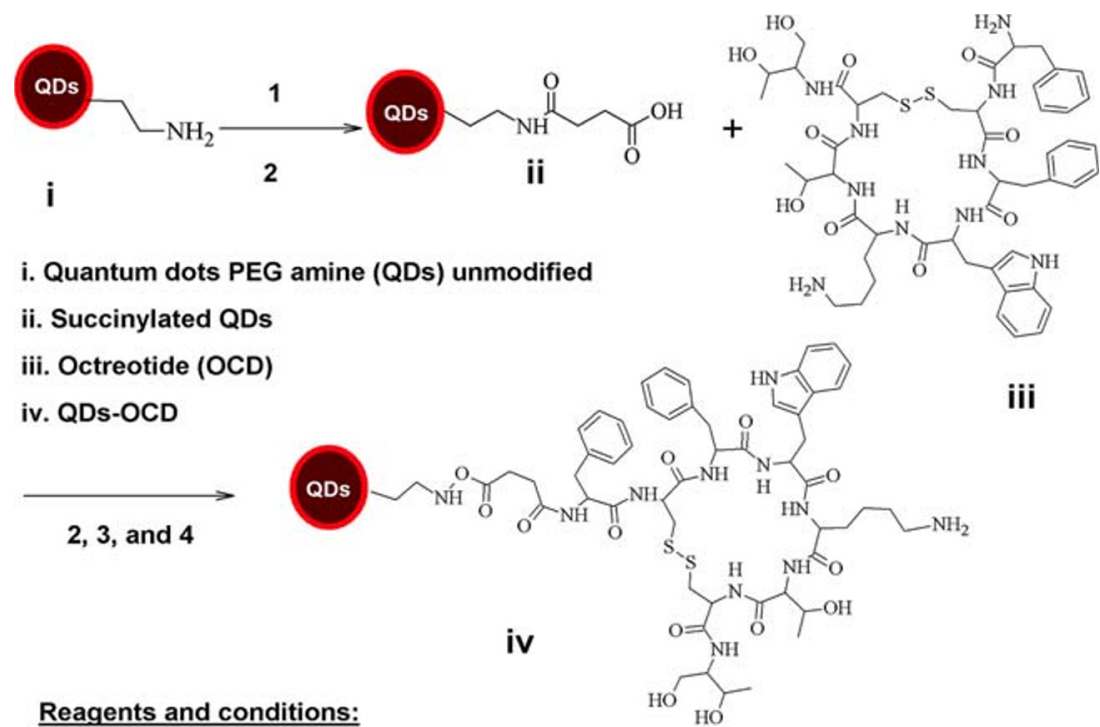

Succinic anhydride (eq. molar), $\mathrm{pH} 7,1 \mathrm{~h}$, BPS; 2). NHS + EDC (2 eq); 3). Octreotide (100 eq), pH 6, aq medium, $3 \mathrm{~h}$; 4). Purification (centrifugation $/ 2000 \mathrm{~g} /$ $10 \mathrm{~min}$, Sphadex (G-25).

AC300 autosampler spectrometer operating at $300 \mathrm{MHz}$, respectively (Bruker Electronik, Rheinstetten, Germany). Chemical shifts ( $\boldsymbol{\delta}$ in ppm) are given relative to tetramethylsilane $(\mathrm{TMS}=0 \mathrm{ppm})$, as an internal reference standard.

\section{Cellular Uptake Study}

Human pancreatic NET (BON-1) cells and Henrietta Lack family (HeLa) cells were chosen as models of positive SSTR expression, and the human primary glioblastoma cell line U-87 was chosen as a model of negative SSTR expression. Cells were seeded in a 24-well plate in growth medium and permitted to mature for 3 days at a density of 100,000 cells/well. Then, the cells were incubated with $20 \mathrm{nM}$ QDs, QDs-OCD, or QDs$\mathrm{OCD}+100 \mu \mathrm{M}$ free $\mathrm{OCD}$ for $3 \mathrm{~h}$ at $37^{\circ} \mathrm{C}$. The dose was single dose as previously reported protocol by our lab Hennig et al. (27). After incubation, the cells were washed with Dulbecco's phosphate-buffered saline (DPBS), trypsinized, and centrifuged at $300 \times \mathrm{g}$ at $4^{\circ} \mathrm{C}$. FACS was used to identify the internalization of QDs-OCD at 488 and $655 \mathrm{~nm}$ as the excitation and emission wavelengths, respectively. Fluorometric analysis was performed to obtain the concentration of QDs using an LS-55 Perkin Elmer Spectrometer (Waltham, USA) with excitation and emission wavelengths of 488 and $655 \mathrm{~nm}$, respectively $(17,49)$. To analyse the displacement of QDs-OCD from the targeted cells, approximately 10,000 cells were seeded into 8-well Ibed chamber slides (Berlin, Germany). A competitive displacement investigation was carried out by mixing the QDs-OCD with a $100 \mu \mathrm{M}$ of free OCD for $1 \mathrm{~h}$ at $37^{\circ} \mathrm{C}$ (49). Then, the cells were investigated using a Zeiss Axiovert $200 \mathrm{M}$ inverted epifluorescence microscope (Munich, Germany) with $488 \mathrm{~nm} / 655 \mathrm{~nm}$ as the excitation and emission wavelengths, respectively (7).

\section{Animal Study}

Animal handling and work were approved and performed under the relevant guidelines and regulations by Regierung der Oberpfalz, reference no. 54-2532, 1-23/11. Male albino mice with a bodyweight of 35-40 $\pm 0.5 \mathrm{~g}$ and an age of approximately 4-5 months were used for the in vivo study, as previously reported by Pollinger et al. (50). Each mouse was injected intraperitoneally (IP) with $55 \mu \mathrm{L}$ of a mixture of ketamine and xylazine (3:1). The reported doses of ketamine and xylazine were $100 \mathrm{mg} / \mathrm{kg}$ and $10 \mathrm{mg} / \mathrm{kg}$, respectively (37). Then, mice were injected with QDs and QDs-OCD (100 pmole) into the lateral vein (50). One hour post-injection, the mice were sacrificed, and the organs were fixed with $4 \%$ PFA and left overnight. The kidney, eyes, colon, lung, heart, pancreas, and liver were obtained and fixed in tissueTek gel after being frozen with liquid nitrogen, and then stored at $-40 \pm 0.5^{\circ} \mathrm{C}$. The obtained organs were cut into $10 \mu \mathrm{m}$-thick slices using a cryotome. Then, the organ sections were displayed on charged slides from Fisher Scientific (Pittsburgh, USA) and imaged by CLSM (7).

Determination of Cadmium Mass. The distribution of QDsOCD was studied by quantifying the amount of cadmium $(\mathrm{Cd})$ in all organs using a $7700 \mathrm{cx}$ inductively coupled plasma mass spectrometry (ICP-MS) instrument (Agilent Technologies, Santa Clara, USA) as described in previous studies $(34,60)$. Briefly, samples were harvested, washed in DPBS, and digested using the microwaveassisted nitric acid digestion method (MARSX press system $(\mathrm{CEM}))$. The content of $\mathrm{Cd}$ quantitatively represented the number of QDs in all tissues. The total injected dose (ID) was calculated by adding the $\mathrm{Cd}$ mass of all organs (7). 
Determination of Blood Fluorescent QDs-OCD. The amount of internalized QDs-OCD in the blood cells was determined by centrifugation of the blood samples at $5000 \mathrm{rpm}$, and the resulting blood serum was used. The fluorescence of the unmodified QDs and QDs-OCD was recorded using a PerkinElmer LS 55 (Rodgau, Germany) (11).

Statistical Analysis. ANOVA was performed to study the statistics of the generated data using Minitab 17 statistical software with Tukey's comparison model. Statistical analysis was conducted for the cellular uptake and animal work. Statistically, significance was recorded when $p \leq 0.05$.

\section{RESULTS}

\section{QDs Characterization}

A stable QDs-OCD nanoparticle solution was obtained and confirmed from the pronounced fluorescence emission spectra with a slight non-significant blueshift compared with the QDs alone. The observed blueshift was attributed to the conjugation of QDs with OCD. In addition, the particle diameter size for the QDs-OCD was $283.3 \pm 17.0 \mathrm{~nm}$ compared to 267.0 $\pm 23.0 \mathrm{~nm}$ for GEG amine due to coating with OCD as measured by the Zetasizer Nano. Furthermore, a zeta potential study revealed successful conjugation between the QDs and OCD, as revealed by inversion of the zeta potential value. Unmodified QDs and QDs coated with OCD showed inversion of the zeta potential value from negative $(-22.4 \pm$ $0.56 \mathrm{mV}$ ) for unmodified QDs to positive for QDs-OCD $(+11.5 \pm 0.27 \mathrm{mV})$. The zeta potential value indicated the stability of the produced nanoparticle dispersion (26).

The conjugation of QDs with OCD was finally proved using ${ }^{1} \mathrm{H}-\mathrm{NMR}$ spectroscopy. ${ }^{1} \mathrm{H}-\mathrm{NMR}$ spectra of OCD, QDs and QDs-OCD in deuterated methanol (CD3OD) are illustrated in (supplementary data S1). ${ }^{1} \mathrm{H}-\mathrm{NMR}$ proved the successful functionalization of QDs carrying PEG-amine end groups with succinic anhydride. The modification of the amine group of QDsPEG-amine (unmodified) by succinic anhydride is characterized by the appearance of succinate peaks beside those of PEG. Succinate protons were used as internal standard (area I, at 2.5$2.8 \mathrm{ppm})$. Additionally, the PEG protons were detected in the region of area II at 3.4-3.8 ppm before and after conjugation with OCD, confirming the stability of QDs during the process of conjugation. The aromatic peaks at 7.00-7.50 ppm (area III) were used as indicator for the presence of OCD conjugated to QDs.

However, the product showed also the presence of some impurities such as methanol or water. This is due to the incomplete process of purification of unmodified and formulated QDs which could not be further confirmed, since the QDsOCD are very sensitive to the harsh purification and drying procedure which may damage the nanoparticles. The coupling reaction of QDs and OCD was completed after $3 \mathrm{~h}$. However, further investigations are needed to further support this characterization.

FT-IR was used to measure the functional groups of the polymers and peptides decorated nanoparticles $(12,20,22,23,32)$. The main bands of OCD, unmodified QDs, QDs-OCD and physical mixture of QDs \& OCD spectra of the dried samples are shown in (supplementary data S2). The corresponding spectra were smoothened and normalized in order to define the most important bands (S2). FT-IR showed significant differences in the shape and position of peaks between of QDs-OCD and a physical mixture of QDs \& OCD. QDs-OCD exhibit sharp bands at $1634.6 \mathrm{~cm}^{-1}$ and $1564.4 \mathrm{~cm}^{-1}$, which can be attributed to the presence of $(\mathrm{C}=\mathrm{O}$ stretching) of amide group and appearing of sharp bands at $1490 \mathrm{~cm}^{-1}$ and $1500 \mathrm{~cm}^{-1}$ which is attributed to the presence of $(\mathrm{N}$ $\mathrm{H}$ bending) of amide group. The amide bond is formed during the conjugation of OCD to the carboxylic group of succinylated-Qdots. These two distinct bands were found only for QDs-OCD and not in the physical mixture. These findings confirm the successful reaction of conjugation of QDs with OCD using EDC. The bands at $3300 \mathrm{~cm}^{-1}$, are corresponding to N-H stretching vibrations of $\mathrm{NH}_{2}$ from the Lys of OCD. These mean that $\mathrm{NH}_{2}$ of the Lys side chain of OCD does not interact with unmodified QDs (QDs-PEG amine), which is still free.

\section{Cellular Uptake Study}

The cellular uptake study revealed that unmodified QDs did not show any significant uptake when tested in BON-1 cells (Fig. 2, a and b), whereas QDs-OCD showed significant uptake $(p \leq 0.05$, ANOVA/Tukey) with strong fluorescence (Fig. 2, c). The fluorescence of the QDs-OCD appeared as spots in the cytoplasm of the cells due to receptor-mediated endocytosis. This observation suggested the effective targeting of the produced particles into their targeted cells. Interestingly, internalization was reduced after the addition of $100 \mu \mathrm{M}$ OCD as a free agonist, which displaced the QDs-OCD (Fig. 2, d). The active internalization of QDs-OCD into the other cell lines was also studied, e.g., HeLa cells and U-87 cells, and the results were compared with those from the BON-1 cells $(40,46)$. The FC results showed that QDsOCD had a higher internalization into human HeLa cells than into U-87 and BON-1 cells. This could be attributed to the higher expression of $\mathrm{SSTR}_{2}$ in HeLa cells compared with the limited expression observed in the U-87 cell line (Fig. 3) (1).

\section{In Vivo Targeting of Octreotide-Coated QDs}

Animal work showed a significantly ( $p \leq 0.05$, ANOVA/Tukey) higher accumulation of $\mathrm{Cd}$ in the blood compared with the other tested organs, such as the liver and spleen, which represent 
Fig. 2 CLSM images showing the binding of QDs to BON-I cells. $\mathrm{BON}-\mathrm{I}$ cells were incubated with (a) the only medium, (b) QDs (unmodified), (c) the formulated QDs$O C D$, and (d) the formulated QDs-OCD in the presence of free peptide. Each picture is presented as brightfield vs darkfield.

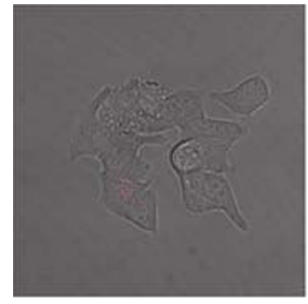

(a) Control (No QDs)

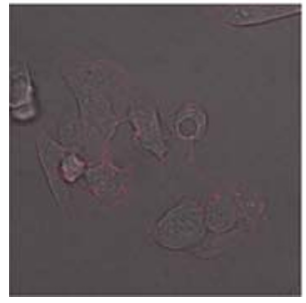

(b) $20 \mathrm{nM}$ QDs (unmodified)
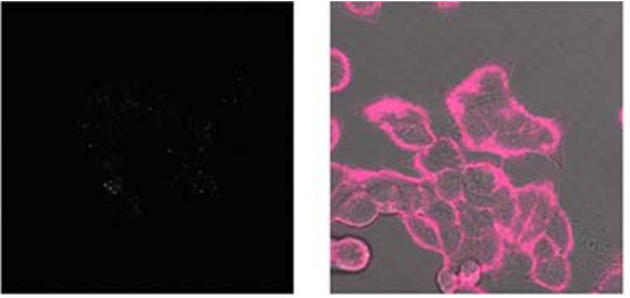

(c) $20 \mathrm{nM}$ QDs-OCD
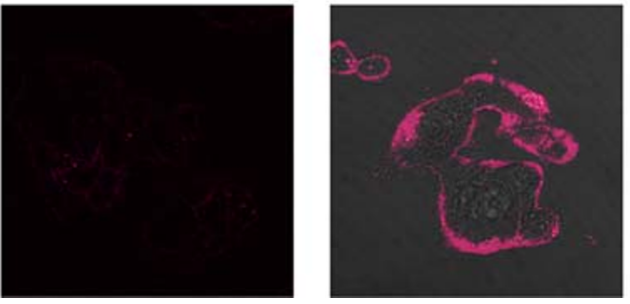

(d) $20 \mathrm{nM}$ QDs-OCD $+100 \mu \mathrm{M}$ free OCD
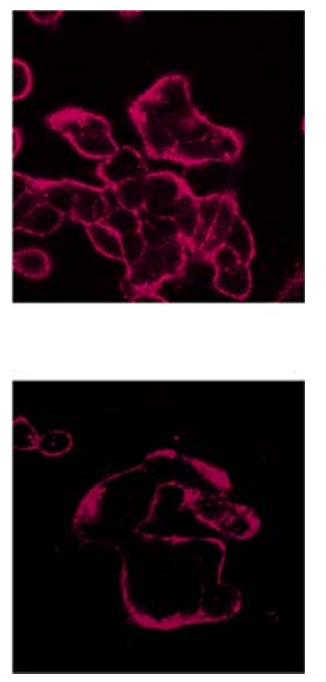

\section{(1)}

digested QDs in the blood (Fig. 4). Approximately $51.78 \pm 3.4 \%$ injected dose per gram of tissue (ID/g $\mathrm{g}_{\text {tissue }}$ ) of QDs-OCD was found in the blood compared to $21.56 \pm 1.3 \%$ and $7.5 \pm 1.22 \%$ of QDs-OCD found in the liver and spleen, respectively, from the total amount of $\mathrm{Cd}$ detected. An in vivo study revealed inhibition of non-specific internalization of QDs-OCD into the liver compared with unmodified QDs. CLSM (Fig. 5) also confirmed this result; liver cells showed no accumulation of QD-OCD particles and subsequently did not detect fluorescence. On the other hand, the particles fluoresced in liver cells in the case of unmodified QDs, which suggested the metabolization of the unmodified QDs. It is also worth noting that the QDs-OCD found in the

blood had a fluorescence peak corresponding to that obtained from the unmodified QDs using ICP-MS (Fig. 4). Furthermore, no QDs were detected in the blood of the placebo mouse serum.

The presence of QDs-OCD in blood was also confirmed by measurements of the fluorescence of injected QDs-OCD compared to the unmodified QDs as shown in the fluorescence spectra obtained from the blood of mice injected with QDs-OCD compared to that of unmodified QDs. Moreover, the data obtained from placebo mouse serum showed no fluorescence and no interference with natural QD fluorescence (Fig. 6). These findings confirmed the large accumulation of QDs-OCD in blood cells due to the overexpression of $\mathrm{SSTR}_{2}$.
Fig. 3 The binding capacity of QDs-OCD with different investigated cell lines as obtained from the flow cytometry study. The binding was reduced in the case of incubation with $100 \mu \mathrm{M}$ free OCD. * Statistically significant uptake with HeLa cells ( $p \leq 0.05$, ANOVA) Tukey) compared to Bon-I and U87 cells. Each data point denotes the average of three measurements ( \pm SEM).

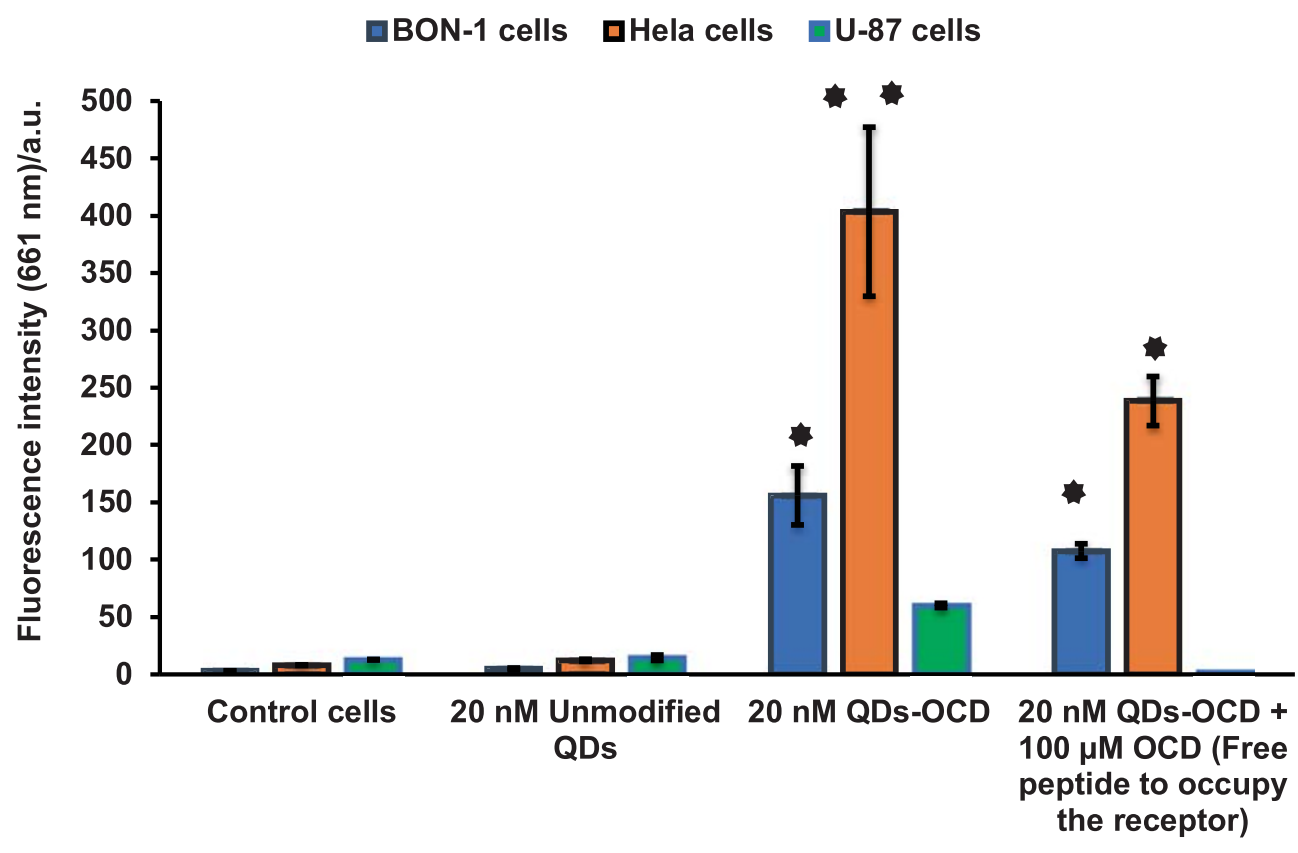




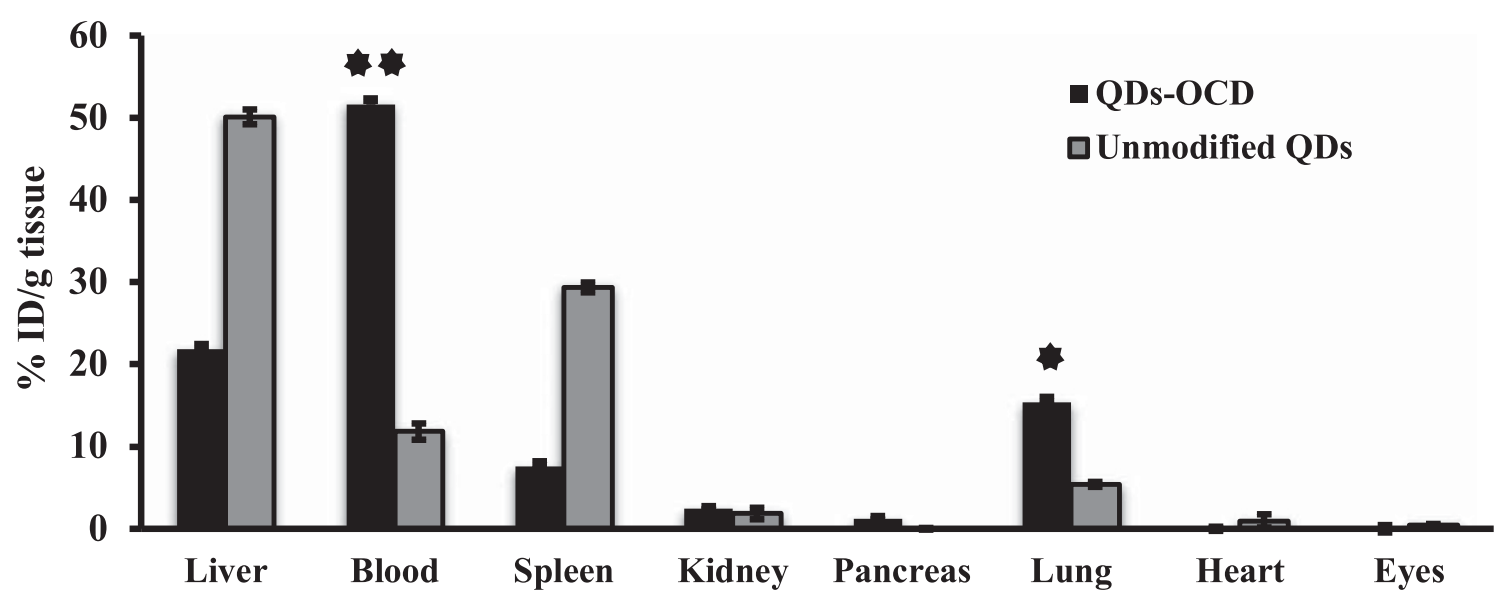

Fig. 4 Unmodified QDs and QDs-OCD bio-distribution in the investigated mouse organs. The measured cadmium amount demonstrates the QD content, whereas ICP-MS was used to determine the amount of Cd to represent the amount of QDs-OCD. * Significant ( $p \leq 0.05$, ANOVA/Tukey) distribution of QDsOCD in the blood compared to other organs; ** Significant ( $p \leq 0.05$, ANOVA/Tukey) distribution of QDs-OCD in the compared to the other organs. Each data point denotes the average of three measurements ( \pm SEM).

\section{DISCUSSION}

Active targeting to specific kinds of cells and/or receptors has gained increasing attention from researchers working with different organ disorders and cancers, especially compared with passive targeting. Additionally, the carrier system is very important as the receptor analogue for efficient targeting and therapy. Coupling between the targeting moiety and the carrier depends on the chemical structure, reaction medium, and availability of selective groups for conjugation. In this study, OCD was conjugated with QDs-PEG amine (unmodified) at the selective N-terminus of OCD under low $\mathrm{pH}$ conditions to produce an effective targeting moiety, QDsOCD, in a stable colloidal dispersion. Many groups could affect the reaction and formation of conjugates, such as sulfhydryl groups, which are essential for the completion of
Fig. 5 Mouse liver tissues were examined using CLSM after treatment with 100 pmole unmodified QDs and QDs-OCD. (a) Unmodified QDs showed a huge accumulation in liver tissues, whereas (b) QDsOCD did not appear in the liver tissues.
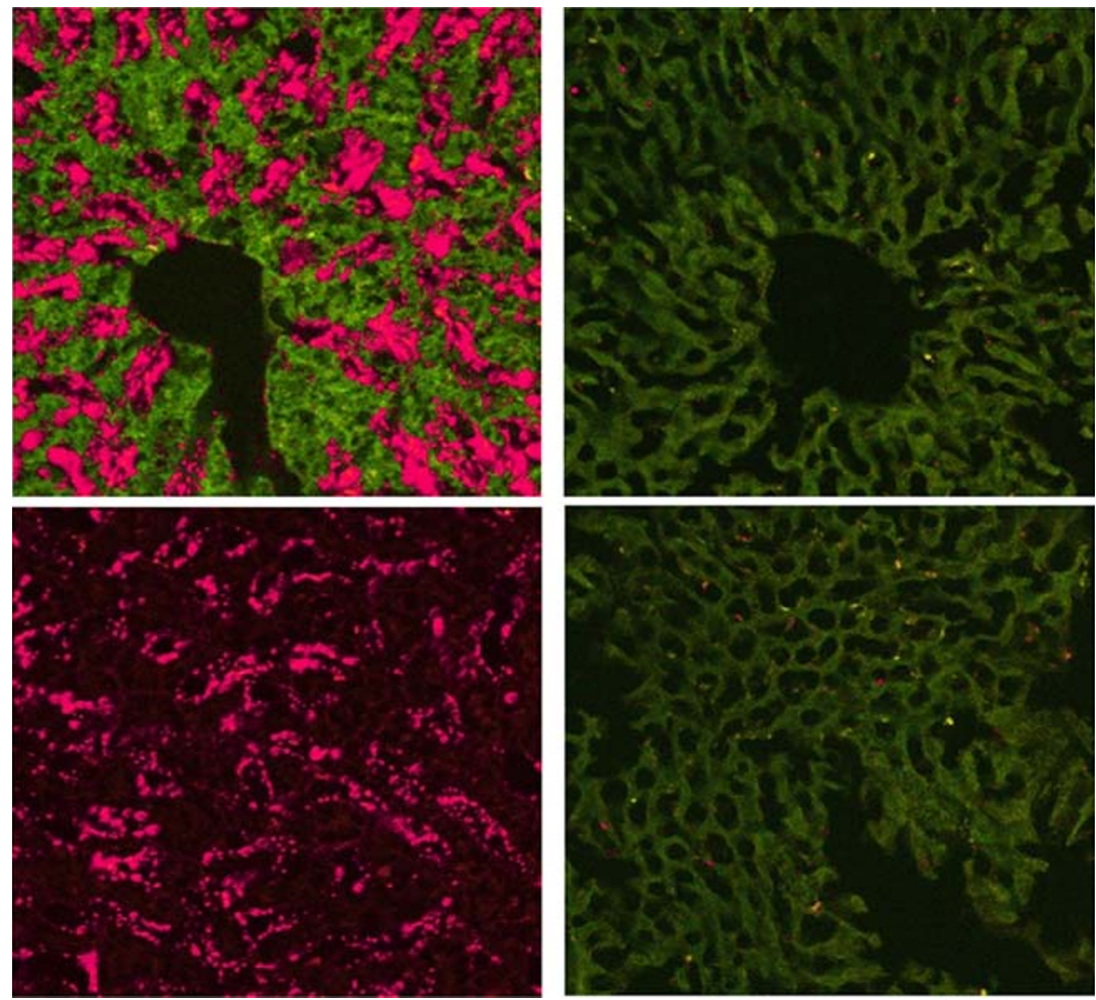

(a) Liver tissues \& Unmodified QDs

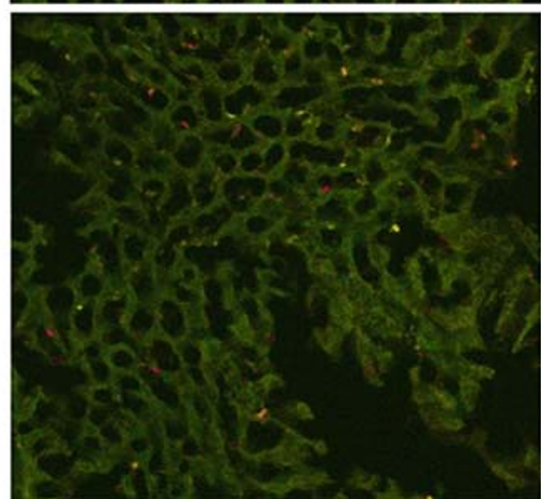

(b) Liver tissues \& QDs-OCD 
Fig. 6 Fluorescence spectrum of QDs-OCD in the blood compared with $20 \mathrm{nM}$ unmodified QDs, and serum of control mouse.

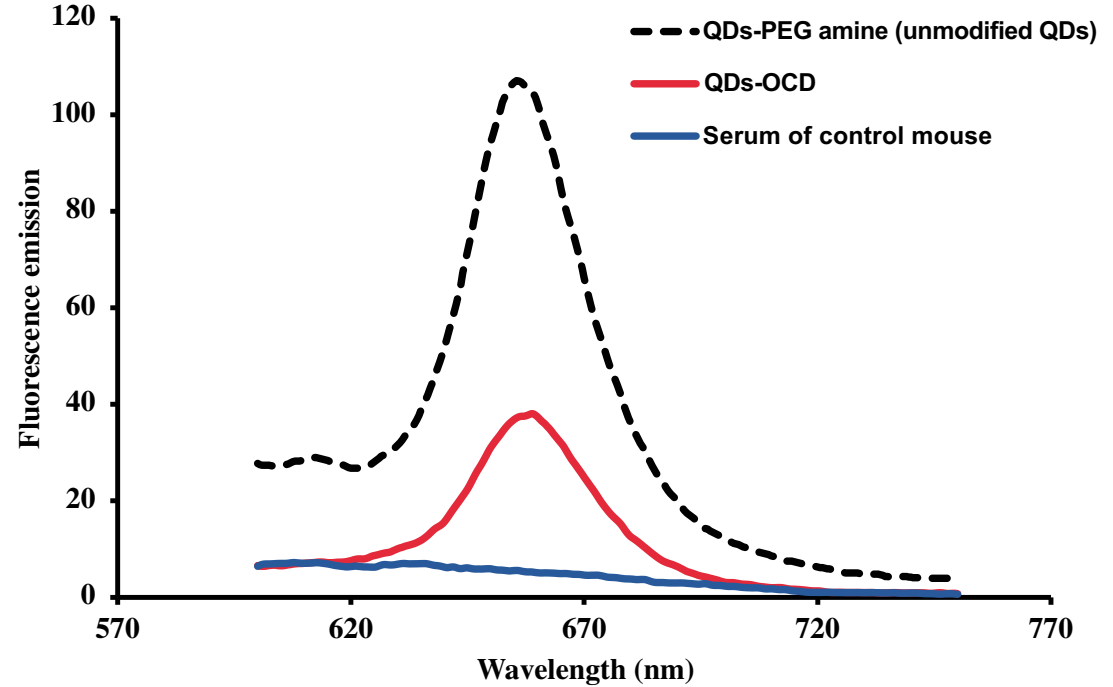

the conjugate. Hence, the addition of EDTA to the reaction medium to chelate all divalent metal ions that can oxidize sulfhydryl groups (6) makes the reaction much more selective. FT-IR spectroscopy and ${ }^{1} \mathrm{H}-\mathrm{NMR}$ confirmed the attachment of OCD to QDs. The ${ }^{1} \mathrm{H}-\mathrm{NMR}$ showed the proton signals of OCD and succinate. In addition, FT-IR showed two carbonyl groups reflecting the covalent bond formation in the conjugated QDs-OCD compared to the physical mixture between the respective components which is not confirmed.

Generally, the particle surface charge and the degree of zeta potential confirm the stability of the colloidal system. The scale of the zeta potential reveals the grade of electrostatic repulsion between neighbouring like charged particles in a dispersion. The prepared QD-OCD conjugate had enough repulsive forces between particles, hence the stability of the prepared colloidal solution (3). Moreover, colloids with high zeta potentials (negative or positive) are considered electronically stabilized, while low zeta potentials lead to coagulation or flocculation of the dispersion medium $(45,55)$. It is also worth noting that a reversal of zeta potential from a negative to a positive value for the unmodified QDs and QDs-OCD, respectively, suggested that the OCD bound to QDs (26). However, a significant blueshift for the formulated QDsOCD confirmed that the unmodified QDs was conjugated to OCD. Interestingly, despite the successful conjugation between the QDs and OCD, the conjugate did not disturb or affect the fluorescence activity of unmodified QDs.

CLSM results supported the results obtained and confirmed that the produced QDs-OCD were actively transported into the investigated cells through interaction with the targeted $\mathrm{SSTR}_{2}$ embedded into the cell surface. QDsOCD were detectible in the cytoplasm of cells upon receptor-mediated endocytosis. Additionally, the fluorescence spectra obtained from FACS confirmed that the particles had the same original fluorescence corresponding to those observed by CLSM. Much more evidence was also gained after studying the internalization capacity using different cell lines with different expression patterns of $\mathrm{SSTR}_{1-5}$. QDs-OCD demonstrated significant internalization with cells that express more receptors on their surface, such as HeLa cells, compared with U-87 cells. Hence, there was selectivity of the produced QDs-OCD system. The higher expression of mRNA in cells containing higher amounts of $\mathrm{SSTR}_{2}$, such as HeLa cells, could also be the cause behind the higher internalization compared with cells showing a lower expression of SSTR mRNA, such as U-87 cells. Furthermore, the fluorescence intensities of QDs-OCD in HeLa cells, U-87 cells, and BON-1 cells were equivalent to those obtained by RT-PGR in our lab (11). Similar results have also been reported regarding gold NPs coated with SST analogues targeting $\operatorname{SSTR}_{1-5}(1,6)$. Interestingly, QDs-OCD showed very low internalization and/or hindrance to transport into the target cells upon the addition of higher amounts of free OCD for blocking the $\mathrm{SSTR}_{2}$, which means that the higher internalization of particles was due to transport through interaction with $\mathrm{SSTR}_{2}$. The large $\mathrm{Cd}$ content in the blood is due to the circulation of OCD-coated QDs as the OCD bound to the $\mathrm{SSTR}_{2}$ in blood cells (2). It has been reported that $\mathrm{SSTR}_{1-5}$ are overexpressed on the surface of monocytes $(14,39,42,47,48,52,59)$.

Hence, these QDs-OCD facilitate targeting and early diagnosis of leukaemia. The formulated system could also have the potential for a long circulation time in the blood and a long lifespan in monocytes, as the OCD was conjugated to the QDs via space from the PEG-amine. (30). The PEG layer around the NPs can reduce the adsorption of opsonins and the rapid clearance of $\mathrm{NPs}$, which is preferred in cancer therapy $(53,58,61)$. On the other hand, unmodified QDs accumulated in the liver due to rapid lymphatic uptake and non-binding to $\operatorname{SSTR}_{1-5}$. (2). The impact of this finding is the accumulation of QDs-OCD in blood. Pollinger et al. formulated the QDs as RGD-modified QDs (50), the study showed a large accumulation of unmodified QDs as well as Qdots-c(RGDFG) in the liver and spleen, while only small 
amounts were found in blood. The liver accumulated $50.1 \%$ $\mathrm{ID} / \mathrm{g}_{\text {tissue }}$, the spleen accumulated $29.36 \% \mathrm{ID} / \mathrm{g}_{\text {tissue }}$, while only $11.8 \% \mathrm{ID} / \mathrm{g}_{\text {tissue }}$ circulated in the blood. Results showed that OCD can target the blood with avoidance of toxic effect on the liver. All other organs showed negligible uptake of QDsOCD (supplementary 3). While lung showed some accumulations of QDs-OCD which also due the expression of SSTR ${ }_{1-5}$ on lung cells $(33,38)$. This kind of targeting is selective, very specific and has the potential to target blood cell diseases such as leukaemia. Further studies will proceed in leukaemic models to investigate the potential of the prepared system for the treatment of blood cancer and effective therapy compared with other possible medications.

\section{CONCLUSIONS}

QDs were successfully conjugated with OCD to give a stable colloidal dispersion, as indicated from the emission absorption spectra. QDs-OCD could target and bind selectively with cells expressing higher amounts of $\mathrm{SSTR}_{2}$, such as HeLa cells, compared with those expressing lower amounts of $\mathrm{SSTR}_{2}$, e.g., U-87 cells. Moreover, the produced system had superior potential for targeting blood monocytes than other organs, such as the liver, spleen, and eye. The formulated QDsOCD showed a minimum clearance from blood monocytes via the lymphatic system to drain into the liver. As well as they remained in the blood for a relatively long time as measured from $3 \mathrm{~h}$ experiment time. Future studies will consider the effectiveness of the proposed system in different organs with empathize on the toxicity and pharmacokinetic profiles manipulations. Hence, this system offers a great advantage for selective targeting of blood cells with higher therapeutic efficiency.

\section{ACKNOWLEDGMENTS AND DISCLOSURES}

The researchers would like to thank the Deanship of Scientific Research, Qassim University, for support of this project. The authors declare no conflicts of interest.

\section{REFERENCES}

1. Abdellatif A. Octreotide labelled fluorescein isothiocyanate for identification of somatostatin receptor subtype 2. Biochem Physiol. 2015;4(183):2.

2. Abdellatif AAH. A plausible way for excretion of metal nanoparticles active targeting. Drug Dev Ind Pharm. 2020;46(5):744-50.

3. Abdellatif, A.A.H., Tawfeek, H.M. Transfersomal Nanoparticles for Enhanced Transdermal Delivery of Clindamycin. AAPS PharmSciTech. 2016;17:1067-74.https://doi.org/10.1208/ s12249-015-0441-7.
4. Abdellatif AA, Zaki AM, Abdo HM, Aly DG, Emara TA, ElToukhy S, et al. Assessment of serum levels of granulocytemacrophage colony-stimulating factor (GM-CSF) among nonsegmental vitiligo patients: a pilot study. Acta Dermatovenerol Alp Pannonica Adriat. 2015;24(3):43-5.

5. Abdellatif AA, Zayed G, El-Bakry A, Zaky A, Saleem IY, Tawfeek HM. Novel gold nanoparticles coated with somatostatin as a potential delivery system for targeting somatostatin receptors. Drug Dev Ind Pharm. 2016;42(11):1782-91.

6. Abdellatif AA, Tawfeek H. Development and evaluation of fluorescent gold nanoparticles. Drug Dev Ind Pharm. 2019;44(10):1679716 .

7. Abdellatif AAH, Abou-Taleb HA, Abd El Ghany AA, Lutz I, Bouazzaoui A. Targeting of somatostatin receptors expressed in blood cells using quantum dots coated with vapreotide. Saudi Pharm J. 2018;26(8):1162-9.

8. Abdellatif AAH, Aldalaen SM, Faisal W, Tawfeek HM. Somatostatin receptors as a new active targeting sites for nanoparticles. Saudi Pharm J. 2018;26(7):1051-9.

9. Ahmed A. H. Abdellatif. Identification of somatostatin receptors using labeled PEGylated octreotide, as an active internalization, Drug Dev Ind Pharm. 2019:45(10):1707-15. https://doi.org/10. 1080/03639045.2019.1656735.

10. Abdellatif AAH, Abdelhafez WA, Sarhan HA. Somatostatin decorated quantum dots nanoparticles for targeting of somatostatin receptors \%. J Iran J Pharm Res. 2018;17(2):513-24.

11. Xu T, Zhang Q Fan YH, Li RQ Lu H, Zhao SM, Jiang TL. Quantitative and multiplexed detection for blood typing based on quantum dot-magnetic bead assay. Int J Nanomedicine. 2017;12: 3347-56. https://doi.org/10.2147/IJN.S133247.

12. Badia A, Cuccia L, Demers L, Morin F, Lennox RB. Structure and dynamics in alkanethiolate monolayers self-assembled on gold nanoparticles: a DSC, FT-IR, and deuterium NMR study. J Am Chem Soc. 1997;119(11):2682-92.

13. Bertrand N, Leroux JC. The journey of a drug-carrier in the body: an anatomo-physiological perspective. J Control Release. 2012;161(2):152-63.

14. Bhathena SJ, Recant L. Somatostatin receptors on circulating human blood cells. Horm Metab Res. 1980;12(6):277-8.

15. Bhunchu S, Rojsitthisak P. Biopolymeric alginate-chitosan nanoparticles as drug delivery carriers for cancer therapy. Pharmazie. 2014;69(8):563-70.

16. Botha MC, Jones M, de Klerk WA, Yamamoto N. Distribution and possible spread of human T-cell leukaemia virus type I in human communities in the northern and eastern Transvaal. S Afr Med J. 1985;67(17):668-71.

17. Cai W, Chen X. Preparation of peptide-conjugated quantum dots for tumor vasculature-targeted imaging. Nat Protoc. 2008;3(1):8996.

18. Cantarella CD, Ragusa D, Giammanco M, Tosi S. Folate deficiency as predisposing factor for childhood leukaemia: a review of the literature. Genes Nutr. 2017;12:14.

19. Chavez-Gonzalez A, Bakhshinejad B, Pakravan K, Guzman ML, Babashah S. Novel strategies for targeting leukemia stem cells: sounding the death knell for blood cancer. Cell Oncol (Dordr). 2017;40(1):1-20.

20. Dassenoy F, Philippot K, Ould-Ely T, Amiens C, Lecante P, Snoeck E, et al. Platinum nanoparticles stabilized by $\mathrm{CO}$ and octanethiol ligands or polymers: FT-IR, NMR, HREM and WAXS studies. New J Chem. 1998;22(7):703-11.

21. Demaree CJ, Soliz JM, Gebhardt R. Cancer seeding risk from an epidural blood patch in patients with leukemia or lymphoma. Pain Med. 2017;18(4):786-90.

22. Abdellatif, A.A.H., Ibrahim, M.A., Amin, M.A. et al. Cetuximab Conjugated with Octreotide and Entrapped Calcium Alginate- 
beads for Targeting Somatostatin Receptors. Sci Rep. 2020;10: 4736.https://doi.org/10.1038/s41598-020-61605-y.

23. Diaz-Visurraga J, Daza C, Pozo C, Becerra A, von Plessing C, Garcia A. Study on antibacterial alginate-stabilized copper nanoparticles by FT-IR and 2D-IR correlation spectroscopy. Int J Nanomedicine. 2012;7:3597-612.

24. Edrees BM, Athar M, Abduljaleel Z, Al-Allaf FA, Taher MM, Khan W, et al. Functional alterations due to amino acid changes and evolutionary comparative analysis of ARPKD and ADPKD genes. Genom Data. 2016;10:127-34.

25. Greaves M. Leukaemia 'firsts' in cancer research and treatment. Nat Rev Cancer. 2016;16(3):163-72.

26. Greenwood R, Kendall K. Selection of suitable dispersants for aqueous suspensions of zirconia and titania powders using acoustophoresis. J Eur Ceram Soc. 1999;19(4):479-88.

27. Hennig R, Pollinger K, Tessmar J, Goepferich A. Multivalent targeting of AT 1 receptors with angiotensin II-functionalized nanoparticles. J Drug Target. 2015;23(7-8):681-9.

28. Hiruma K, Koike T, Nakamura H, Sumida T, Maeda T, Tomioka H, Yoshida S, Fujita T. Somatostatin receptors on human lymphocytes and leukaemia cells. Immunology. 1990;71(4):480-5.

29. Hohla F, Buchholz S, Schally AV, Krishan A, Rick FG, Szalontay L, Papadia A, Halmos G, Koster F, Aigner E, Datz C, Seitz S. Targeted cytotoxic somatostatin analog AN-162 inhibits growth of human colon carcinomas and increases sensitivity of doxorubicin resistant murine leukemia cells. Cancer Lett. 2010;294(1):35-42.

30. Huang H, Wang D, Zhang Y, Zhou Y, Geng J, Chitgupi U, Cook TR, Xia J, Lovell JF. Axial PEGylation of tin octabutoxy naphthalocyanine extends blood circulation for photoacoustic vascular imaging. Bioconjug Chem. 2016;27(7):1574-8.

31. Ishihara S, Hassan S, Kinoshita Y, Moriyama N, Fukuda R, Maekawa T, Okada A, Chiba T. Growth inhibitory effects of somatostatin on human leukemia cell lines mediated by somatostatin receptor subtype 1. Peptides. 1999;20(3):313-8.

32. Juarez R, Parker SF, Goncepcion P, Corma A, Garcia H. Heterolytic and heterotopic dissociation of hydrogen on ceriasupported gold nanoparticles. Combined inelastic neutron scattering and FT-IR spectroscopic study on the nature and reactivity of surface hydrogen species. Chem Sci. 2010;1(6):731-8.

33. Kanakis G, Grimelius L, Spathis A, Tringidou R, Rassidakis GZ, Oberg K, et al. Expression of somatostatin receptors 1-5 and dopamine receptor 2 in lung carcinoids: implications for a therapeutic role. Neuroendocrinology. 2015;101(3):211-22.

34. Kane PF, Hall WL Jr. Determination of arsenic, cadmium, cobalt, chromium, lead, molybdenum, nickel, and selenium in fertilizers by microwave digestion and inductively coupled plasma-optical emission spectrometry detection: collaborative study. J AOAC Int. 2006;89(6):1447-66.

35. Kidwai SA, Ansari AA, Salahuddin A. Effect of succinylation (3Carboxypropionylation) on conformation and immunological activity of ovalbumin. Biochem J. 1976;155(1):171-80.

36. Kinstler OB, Brems DN, Lauren SL, Paige AG, Hamburger JB, Treuheit MJ. Characterization and stability of N-terminally PEGylated rhG-CSF. Pharm Res. 1996;13(7):996-1002.

37. Kumar AH, Clover AJ. Intraperitoneal co-administration of low dose urethane with xylazine and ketamine for extended duration of surgical anesthesia in rats. Lab Anim Res. 2015;31(4):174-9.

38. Lapa C, Hanscheid H, Wild V, Pelzer T, Schirbel A, Werner RA, et al. Somatostatin receptor expression in small cell lung cancer as a prognostic marker and a target for peptide receptor radionuclide therapy. Oncotarget. 2016;7(15):20033-40.

39. Lichtenauer-Kaligis EG, Dalm VA, Oomen SP, Mooij DM, van Hagen PM, Lamberts SW, Hofland LJ. Differential expression of somatostatin receptor subtypes in human peripheral blood mononuclear cell subsets. Eur J Endocrinol. 2004;150(4):565-77.
40. Merrell. Octreotide scintigraphy. A new method for diagnosing pancreatic tumors. Ann Surg. 1996;224(2):117-8.

41. Monti G, Schrijver R, Beier D. Genetic diversity and spread of bovine leukaemia virus isolates in argentine dairy cattle. Arch Virol. 2005;150(3):443-58.

42. Muscarella LA, D'Alessandro V, la Torre A, Copetti M, De Cata A, Parrella $\mathrm{P}$, et al. Gene expression of somatostatin receptor subtypes SSTR2a, SSTR3 and SSTR5 in peripheral blood of neuroendocrine lung cancer affected patients. Cell Oncol (Dordr). $2011 ; 34(5): 435-41$

43. Na DH, Murty SB, Lee KG, Thanoo BC, DeLuca PP. Preparation and stability of poly(ethylene glycol) (PEG)ylated octreotide for application to microsphere delivery. AAPS PharmSciTech. 2003;4(4):E72.

44. Oomen SP, Lichtenauer-Kaligis EG, Verplanke N, Hofland J, Lamberts SW, Lowenberg B, et al. Somatostatin induces migration of acute myeloid leukemia cells via activation of somatostatin receptor subtype 2. Leukemia. 2001;15(4):621-7.

45. Ostolska I, Wisniewska M. Application of the zeta potential measurements to explanation of colloidal $\mathrm{Cr} 2 \mathrm{O} 3$ stability mechanism in the presence of the ionic polyamino acids. Colloid Polym Sci. 2014;292(10):2453-64

46. Parekh D, Ishizuka J, Townsend CMJr, Haber B, Beauchamp RD, Karp G, Kim SW, Rajaraman S, Greeley G Jr, Thompson JC. Characterization of a human pancreatic carcinoid in vitro: morphology, amine and peptide storage, and secretion. Pancreas. 1994;9(1):83-90.

47. Perez J, Viollet C, Doublier S, Videau C, Epelbaum J, Baud L. Somatostatin binds to murine macrophages through two distinct subsets of receptors. J Neuroimmunol. 2003;138(1-2):38-44.

48. Petrak K. Essential properties of drug-targeting delivery systems. Drug Discov Today. 2005;10(23-24):1667-73.

49. Pollinger K, Hennig R, Breunig M, Tessmar J, Ohlmann A, Tamm ER, Witzgall R, Goepferich A. Kidney podocytes as specific targets for cyclo(RGDfC)-modified nanoparticles. Small. 2012;8(21): 3368-75.

50. Pollinger K, Hennig R, Ohlmann A, Fuchshofer R, Wenzel R, Breunig M, Tessmar J, Tamm ER, Goepferich A. Ligandfunctionalized nanoparticles target endothelial cells in retinal capillaries after systemic application. Proc Natl Acad Sci U S A. 2013;110:6115-20.

51. Prakash H, Mazumdar S. Succinylation of cytochrome c investigated by electrospray ionization mass spectrometry: reactive lysine residues. Int J Mass Spectrom. 2009;281(1-2):55-62.

52. Reynaert H, van Rossen E, Uyama N, Chatterjee N, Kumar U, Urbain D, et al. Expression of somatostatin receptors in splanchnic blood vessels of normal and cirrhotic rats. Liver Int. 2007;27(6):825-31.

53. Simsek S, Eroglu H, Kurum B, Ulubayram K. Brain targeting of atorvastatin loaded amphiphilic PLGA-b-PEG nanoparticles. J Microencapsul. 2013;30(1):10-20.

54. Tawfeek HM, Abdellatif AAH, Dennison TJ, Mohammed AR, Sadiq Y, Saleem IY. Colonic delivery of indometacin loaded PGA-co-PDL microparticles coated with Eudragit L100-55 from fast disintegrating tablets. Int J Pharm. 2017;531(1):80-9.

55. Thakur D, Jain A, Ghoshal G, Shivhare US, Katare OP. Microencapsulation of beta-carotene based on casein/guar gum blend using zeta potential-yield stress phenomenon: an approach to enhance photo-stability and retention of functionality. AAPS PharmSciTech. 2017;18(5):1447-59.

56. Todisco M. Chronic lymphocytic leukemia: long-lasting remission with combination of cyclophosphamide, somatostatin, bromocriptine, retinoids, melatonin, and ACTH. Cancer Biother Radiopharm. 2009;24(3):353-5.

57. Updegrove TB, Correia JJ, Chen Y, Terry C, Wartell RM. The stoichiometry of the Escherichia coli Hfq protein bound to RNA. RNA. 2011;17(3):489-500. 
58. Vannucci L, Falvo E, Fornara M, Di Micco P, Benada O, Krizan J, et al. Selective targeting of melanoma by PEG-masked proteinbased multifunctional nanoparticles. Int J Nanomedicine. 2012; 7: 1489-509.

59. ter Veld F, Herder C, Mussmann R, Martin S, Kempf K. Somatostatin receptor expression in peripheral blood of type 2 diabetes mellitus patients. Horm Metab Res. 2007;39(3):230-2.

60. Wang YF, Shi YZ, Zhang H, Chen YH, Lau J, Wilbur S, et al. Determination of lead, cadmium, mercury, chromium and arsenic in acrylonitrile-butadiene-styrene copolymer using microwave
digestion-ICP-MS. Guang Pu Xue Yu Guang Pu Fen Xi. 2008;28(1):191-4.

61. Xin H, Sha X, Jiang X, Zhang W, Chen L, Fang X. Antiglioblastoma efficacy and safety of paclitaxel-loading angiopepconjugated dual targeting PEG-PCL nanoparticles. Biomaterials. 2012;33(32):8167-76.

62. Zahr AS, Davis CA, Pishko MV. Macrophage uptake of core-shell nanoparticles surface modified with poly(ethylene glycol). Langmuir. 2006;22(19):8178-85.

Publisher's Note Springer Nature remains neutral with regard to jurisdictional claims in published maps and institutional affiliations. 